\title{
Supported carbon nanofibers for the fixed-bed synthesis of styrene ${ }^{\text {\# }}$
}

\author{
Juan J. Delgado a , Ricardo Vieira ${ }^{\mathrm{b}}$, Guillaume Rebmann ${ }^{\mathrm{b}}$, Dang Sheng Su ${ }^{\mathrm{a}, *}$, \\ Nicolas Keller $^{\mathrm{b}, *}$, Marc J. Ledoux ${ }^{\mathrm{b}}$, Robert Schlögl ${ }^{\mathrm{a}}$ \\ ${ }^{a}$ Fritz Haber Institute of the Max Planck Gesellschaft, Department of Inorganic Chemistry, Faradayweg \\ 4-6, 14195 Berlin, Germany \\ ${ }^{\mathrm{b}}$ Laboratoire des Mate'riaux, Surface et Proce'de's pour la Catalyse, UMR 7515 CNRS, ECPM, Louis \\ Pasteur University, 25 rue Becquerel, 67087 Strasbourg, Cedex 2, France
}

Keywords: Catalyst; Carbon composites; Carbon fibers; Catalytic properties

\footnotetext{
\# This work was realized in the frame of the joint activities of ELCASS (European Laboratory for Catalysis and Surface Sciences).

* Corresponding authors. Tel.: +49 30841354 06; fax: +49 3084134405 (D.S. Su), tel.: +33 3902428 11; fax: +33 390242761 (N. Keller); E-mail addresses: dangsheng@fhi-berlin.mpg.de (D.S. Su), nkeller@chimie.ustrasbg.fr (N. Keller).
}

The styrene synthesis is one of the ten largest industrial processes. This monomer is involved in several polymer syntheses, and is industrially produced by the direct dehydrogenation of ethylbenzene at $873-953 \mathrm{~K}$ over a potassium promoted iron oxide catalyst [1]. This strongly endothermic process suffers from drawbacks such as thermodynamic limitations, a large amount of wasted energy, an irreversible catalyst deactivation and coke deposition [2]. Among the alternative technologies developed, the exothermic and non-thermodynamically-limited oxidative dehydrogenation (ODH) of ethylbenzene is promising. Carbon is reported to be catalytically active for the reaction [3,4]. It has been shown that high performances could be obtained over onion-like carbons and carbon nanotubes [5-8], such non-planar $\mathrm{sp}^{2}$-nanocarbons being very active and promising alternative catalysts to the industrial catalyst, with a higher styrene yield and a lower reaction temperature. The nanocarbons also remained more stable against combustion in an oxidative atmosphere than active carbon [7,8]. A redox mechanism at the carbon surface has been put forward [4-9], involving the oxygen activation on metallic basal planes and the ethylbenzene dehydrogenation on nucleophilic Bronsted basic $-\mathrm{C}=\mathrm{O}$ groups at the edge/kink sites [6,7].

However, the powdery primary form of such nanocarbons is highly detrimental to a use in fixedbed reactors for industrial applications. They are prone to block fixedbed reactors, resulting in pressure drops, and leading to moving-bed phenomena; they are excessively difficult to handle and their suprastructural properties cannot be controlled. Since post-synthesis shaping by compaction changes the chemical properties of the nanocarbon materials and inhibits diffusion of reactants and products inside the compacted material, we gave a macroscopic design to the nanocarbons, by anchoring them onto a macroscopic carbon felt support with an open structure. The carbon felt maintains the continuity of chemical properties with the nanocarbons, and shows a higher resistance towards combustion than active carbon and a higher thermal conductivity than alumina, being thus a stable support that can also prevent the appearance of hot spots during the exothermic ODH reaction.

Immobilized carbon nanofibers were obtained following the process described in Ref. [10], by catalytic chemical vapor decomposition of a mixture of ethane and hydrogen (1:5) at $700^{\circ} \mathrm{C}$ over metallic nickel (1 wt.\%) supported on the non-porous carbon felt (surface area $<1 \mathrm{~m} 2 / \mathrm{g}-$ Carbone Lorraine). Detailed synthesis and characterization can be found elsewhere [10]. A growth for $2 \mathrm{~h}$ led to a weight increase of $100 \mathrm{wt} . \%$, with an increase in the surface area of the 
material to $100 \mathrm{~m} 2 / \mathrm{g}$. The high external surface area of the composite results from the prismatic planes exposed at the outer surface of the nanofibers. The carbon atoms at the edge sites are more reactive than atoms located in the interior of the graphene sheets, and the surface exposed by the carbon nanofibers was thus decorated by oxygenated groups [11]. Each supporting fiber was coated by a network of chinese-hat $40 \mathrm{~nm}$ diameter carbon nanofibers, with a large void volume between each fiber and each nanofiber (Fig. 1). The composite was directly used as catalyst (i) without any post-synthesis shaping and using no binders, (ii) without any purification treatments, due to a high purity resulting from a total selectivity to nanofibers and the high nanofiber yield.

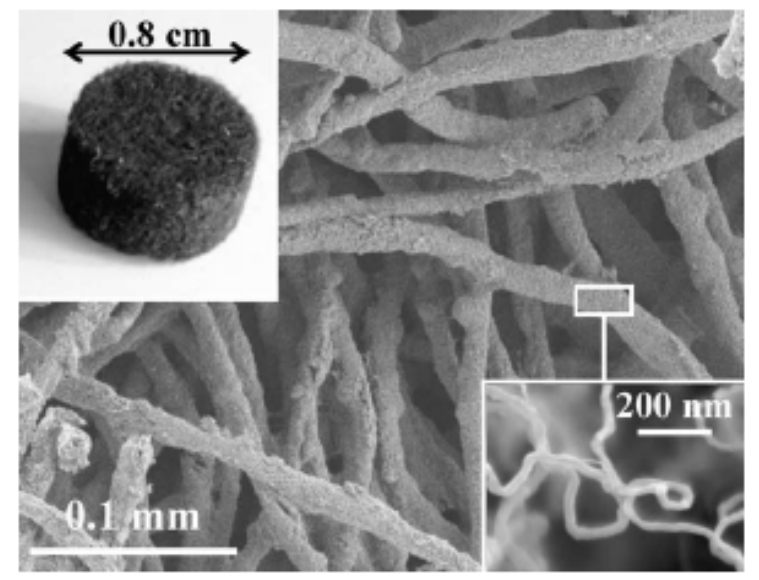

Fig. 1. Optical appearance and SEM image of the nanocarbon composite catalyst.

The felt supported carbon nanofiber composite is an active and selective catalyst even at low temperatures ( 2 vol.\% ethylbenzene, 2 vol.\% oxygen, balance helium) and combines the properties of the nanocarbons and the advantages of the macrostructured felt support. Table 1 shows their performances as a function of time on stream at $425^{\circ} \mathrm{C}$ and $515^{\circ} \mathrm{C}$ at a flow rate of $30 \mathrm{ml} \mathrm{min}^{-1}$. Similarly to powdery $\mathrm{sp}^{2}$-bound nanocarbons [6,7], the macroscopic nanocarbons were stable with time on stream in severe conditions, i.e. a large excess oxygen and the high temperature of $515^{\circ} \mathrm{C}$. This differed from lamp black carbon, which burnt off and deactivated on stream, being totally combusted after $12 \mathrm{~h}$ on stream [8].

Table 1

Conversion of ethylbenzene, selectivity and yield to styrene for different durations on stream

\begin{tabular}{|c|c|c|c|c|c|c|}
\hline \multirow[t]{2}{*}{ Time (h) } & \multicolumn{2}{|c|}{ Ethylbenzene conversion (\%) } & \multicolumn{2}{|c|}{ Styrene selectivity (\%) } & \multicolumn{2}{|c|}{ Styrene yield (\%) } \\
\hline & $425^{\circ} \mathrm{C}$ & $515^{\circ} \mathrm{C}$ & $425^{\circ} \mathrm{C}$ & $515^{\circ} \mathrm{C}$ & $425^{\circ} \mathrm{C}$ & $515^{\circ} \mathrm{C}$ \\
\hline 5 & - & 28.5 & - & 79.4 & - & 22.7 \\
\hline 8 & 19.8 & 28.0 & 86.7 & 80.3 & 17.2 & 22.5 \\
\hline 15 & 19.1 & 27.5 & 88.0 & 78.4 & 17.3 & 21.5 \\
\hline $\mathrm{a}$ & 19.0 & 28.9 & 89.0 & 80.5 & 16.9 & 23.3 \\
\hline
\end{tabular}

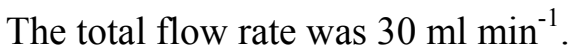

${ }^{a}$ Values after several cycles of increasing/decreasing temperatures.

Fig. 2 shows the performances obtained at temperatures ranging from $375^{\circ} \mathrm{C}$ to $530^{\circ} \mathrm{C}$ for total flows of $30 \mathrm{ml} \mathrm{min}^{-1}$ and $8 \mathrm{ml} \mathrm{min}^{-1}$. Under both conditions, increasing the temperature led to a slight decrease in the styrene selectivity, the carbon balance was mainly closed by $\mathrm{CO}_{2}$. The selectivity was not strongly influenced by the space velocity, with a $2-5 \%$ range increase when increasing the flow, depending on the temperature. By contrast, the space velocity strongly influenced the ethylbenzene conversion, especially for low temperatures for which an absolute 
gain in conversion of $25 \%$ was observed. For both space velocities, the maximum of performances in terms of conversion and styrene yield was dependent on the flow and shifted from $492^{\circ} \mathrm{C}$ to $440^{\circ} \mathrm{C}$ when the flow was decreased (Fig. 2 inset). At a $30 \mathrm{ml} \mathrm{min}{ }^{-1}$ flow, the catalyst showed a maximum of styrene yield of $25 \%$ at a temperature of $492^{\circ} \mathrm{C}$, with a selectivity to styrene of $81 \%$ whereas the yield increased to $38 \%$ at $440^{\circ} \mathrm{C}$ with a similar styrene selectivity at a flow of $8 \mathrm{ml} \mathrm{min}^{-1}$ (see Fig. 3). Comparison with the literature is rather difficult since the nanocarbon performances are directly related to their microstructure, which strongly differs from a nanocarbon to others [6-8]. The porosity of activated carbons also seems to play a negative role by hindering the styrene desorption and favouring non-selective consecutive reactions by artificially increasing the residence time of molecules inside the catalyst [4]. By contrast, the open structure of non-porous macroscopic nanocarbons avoided the material compaction during the test and strongly reduced such non-selective consecutive reactions, allowing high styrene selectivity to be obtained compared to bulk nanocarbons [8].

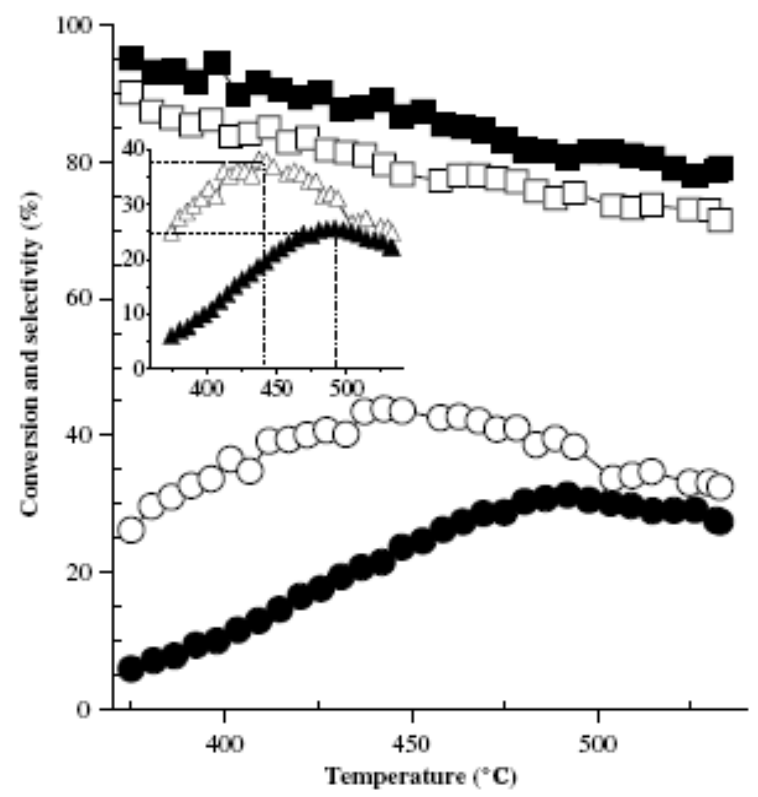

Fig. 2. Ethylbenzene conversions $\circ, \bullet)$ and selectivity to styrene $(\square, \boldsymbol{\square})$ on the macroscopic carbon nanofibers as a function of the reaction temperature in the range $375-530^{\circ} \mathrm{C}$, using a total flow rate of $30 \mathrm{ml} \mathrm{min}^{-1}$ (full symbols) and $8 \mathrm{ml} \mathrm{min}^{-1}$ (empty symbols) respectively. The inset figure shows the resulting styrene yield $(\Delta, \Delta)$ for both flow rates as a function of the temperature.

No oxygen remained in the stream for temperatures higher than that of maximum yield, together with a decrease in the styrene selectivity by the ethylbenzene total oxidation with increasing temperature. The ethylbenzene combustion being more oxygen-demanding than the styrene production, the conversion decreased when part of the oxygen is consumed by total oxidation due to the limited oxygen supply.

Decreasing the space velocity led to a higher ethylbenzene conversion for a given selectivity at a lower temperature. This implies that operating by combining a low temperature $\left(440^{\circ} \mathrm{C}\right)$ and a low space velocity results in high styrene yields (38\%) with a styrene selectivity $(81 \%)$ that could make such supported carbon nanofibers attractive for industrial applications, a low flow favouring reactant adsorption and a low temperature minimizing the combustion. Whatever the reaction conditions, and in particular the space velocity, no pressure drop occurred in the reactor and the catalyst bed. This strongly differed from the high pressure drop observed at similar reaction conditions using nanocarbon powders. The control of the pressure in the catalyst bed is attributed to the open structure of the macroscopic carbon nanofibers. A large void volume remained available between each supporting fibers and the carbon nanofibers themselves, avoiding the restricting problems related to fixed-bed applications of nanomaterial catalysts and 
rendering the whole external surface of carbon nanofibers available for the reactant adsorption. The nanocarbon composite contains $50 \mathrm{wt} . \%$ of inactive very low surface area fibers, with a very low density of sites for oxygen activation and of oxygenated sites for ethylbenzene dehydrogenation. The activity is thus due to the $50 \mathrm{wt} \%$ of immobilized high external surface area nanofibers.

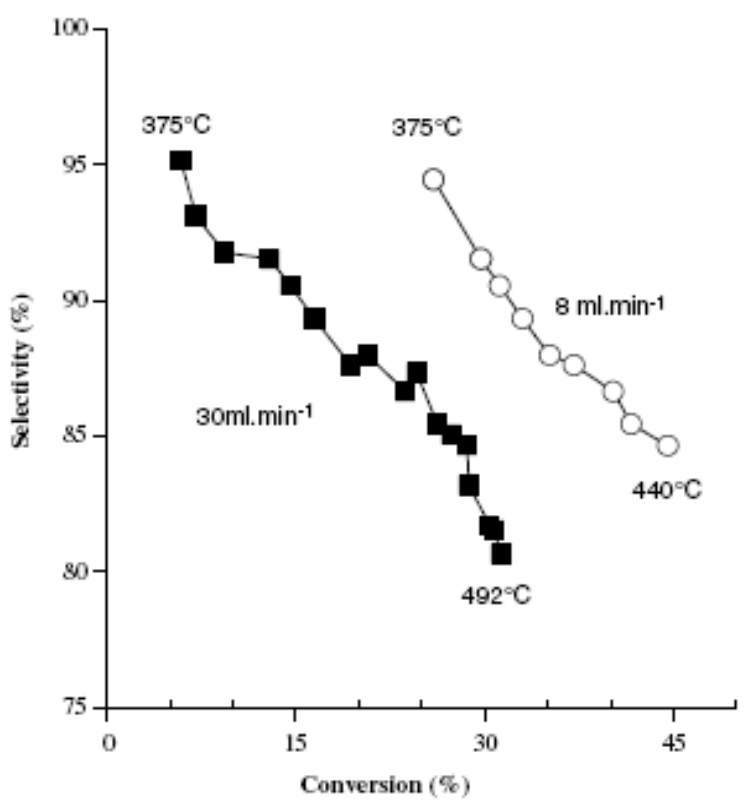

Fig. 3. Ethylbenzene conversion-styrene selectivity plot on the macroscopic carbon nanofibers at total flow rates of $30 \mathrm{ml} \mathrm{min}{ }^{-1}(\mathbf{\square})$ and $8 \mathrm{ml} \mathrm{m^{-1 }}(\circ)$.

Transferring the performances of nanocarbon powders to nanocarbons assembled to a macroscopic shape avoids drawbacks of a powdery primary form and opens routes for designing catalysts for oxydehydrogenation reactions involving hydrocarbons as a general alternative to endothermic thermodynamically-limited direct dehydrogenation reactions.

Acknowledgements

The authors thank N. Maksimova for having been involved in this project. R. Vieira is grateful to the CnpQ (Brasil) for financial support. V. Keller is thanked for fruitful discussion.

\section{References}

[1] James DH, Castor WM. Styrene, Ullmann_s encyclopedia of industrial chemistry, A25. John Wiley \& Sons; 1994. p. 329-44.

[2] Cavani F, Trifiro F., Appl Catal A: Gen 1995;133(2):219-39.

[3] Guerrero-Ruiz A, Rodriguez-Ramos I., Carbon 1994;32(1):23-9.

[4] Pereira MFR, Órfao JJM, Figuereido JL., Appl Catal A: Gen 1999;184(1):153-60.

[5] Mestl G, Maksimova NI, Keller N, Roddatis VV, Schlögl R., Angew Chem Int Ed 2001;40(11):2066-8.

[6] Keller N, Maksimova NI, Roddatis VV, Schur M, Mestl G, Butenko YV, et al., Angew Chem Int Ed 2002;41(11):1885-7.

[7] Su DS, Maksimova N, Delgado JJ, Keller N, Mestl G, Ledoux MJ, et al., Catal Today 2005;102-103:110-4.

[8] Pereira MFR, Figueiredo JL, Órfao JJM, Serp P, Kalck P, Kihn Y., Carbon 2004;42(14):2807-13. 
[9] Maciá-Agulló JA, Cazorla-Amorós D, Linares-Solano A, Wild U, Su DS, Schlögl R., Catal Today 2005;102-103:248-53.

[10] Vieira R, Pham-Huu C, Keller N, Ledoux MJ., Chem Commun 2002:954-5.

[11] Pham-Huu C, Keller N, Roddatis VV, Mestl G, Schlögl R, Ledoux MJ., Phys Chem Chem Phys 2002;4(3):514-21. 